\title{
Marine gastropods and bivalves in the mangrove swamps of Myeik Areas, Taninthayi region, Myanmar
}

\begin{abstract}
The study on species identification, distribution and occurrence of gastropods and bivalves from mangrove swamps of Myeik areas, such as Kyweku, Lighthouse, Inlaymyine and Pahtet were conducted during July 2013 to March 2014 to observe the diverse species, economic importance and their habitats. A total of 23 species belonging to 3 orders, 8 families, 14 genera of gastropods and 6 species belonging to 3 orders, 4 families, 6 genera of bivalves were recorded from the mangrove swamps of study areas. The diverse species of gastropods were found in Kyweku station followed by Lighthouse, Pahtet and Inlaymyine. The bivalves' species were found in Lighthouse followed by Kyweku, Pahtet, and Inlaymyine.
\end{abstract}

Keywords: bivalves, gastropod, mollusks, mangrove, Myeik areas, Taninthayi Region, Myanmar
Volume 8 Issue 3 - 2019

\author{
Hein Zar Htwe,' Naung Naung Oo \\ 'Department of Marine Science, Myeik University, Myanmar \\ ${ }^{2}$ Department of Marine Science, Mawlamyine University, \\ Myanmar
}

Correspondence: Hein Zar Htwe, Department of Marine Science, Myeik University, Taninthayi Region, Myanmar, Email uheinzarhtwe@gmail.com

Received: May 13, 2019| Published: May 24, 2019

\section{Introduction}

In Myeik coastal area, many coral reefs surround the outer islands and mangrove cover much of inner islands. Also, very wide seagrass beds, mudflats and sandy beaches are widespread along the mainland and island coastlines. The warm tropical temperature and monsoon wet season make the region's sea highly productive and supportive of rich and extensive marine habitats. Many small and large island ecosystems with their associated habitats then support a wealth of marine resources.

The mangroves from southern Myeik Archipelago are selectively diverse and is regarded as the area of mangrove where it forms dominant coastal community. There are still very good potentials for further expanse in aquaculture ventures in mangrove swamp areas and mangrove lined waterways. The rearing of edible oyster, mussel, cockle and hard clam can also be developed into large lucrative ventures for both export and domestic consumption. Seashell could play a very important role in providing the much needed food and economic benefits to the local populace. The goal of this study is to elucidate the conchological characters of gastropods and bivalves in selected mangrove swamps of Myeik areas in Myanmar.

\section{Material and methods}

Study areas: The present study was conducted in the mangrove swamp of Myeik Coastal and its adjacent areas that are Kyweku, Lighthouse, Inlaymyine and Pahtet. The location of study areas is shown in Figure 1. Kyweku (Lat. $12^{\circ} 29^{\prime} \mathrm{N}$ and Long. $98^{\circ} 34^{\prime} \mathrm{E}$ ) is located near the human settlement and ship building, and mangrove swamp has about $0.23 \mathrm{~km}^{2}$ where fresh water flow from the Kyauk Phyar river. Lighthouse (Lat. $12^{\circ} 28^{\prime} \mathrm{N}$ and Long. $98^{\circ} 35^{\prime} \mathrm{E}$ ) is located near the human settlement and peddle field, and mangrove swamp has $0.29 \mathrm{~km}^{2}$. Inlaymyine (Lat. $12^{\circ} 24^{\prime} \mathrm{N}$ and Long. $98^{\circ} 38^{\prime} \mathrm{E}$ ) is located near the human settlement and fishery industry, and mangrove swamp has about $0.23 \mathrm{~km}^{2}$ where freshwater flow from the Yaw Gyi River and Taninthayi River. Pahtet (Lat. $12^{\circ} 24^{\prime} \mathrm{N}$ and Long. $98^{\circ} 38^{\prime} \mathrm{E}$ ) has near the mud crab culture farm and fishmeal industry, and mangrove swamp has about $0.06 \mathrm{~km}^{2}$. Tidal rhythm in the study areas regularly occur twice a day.

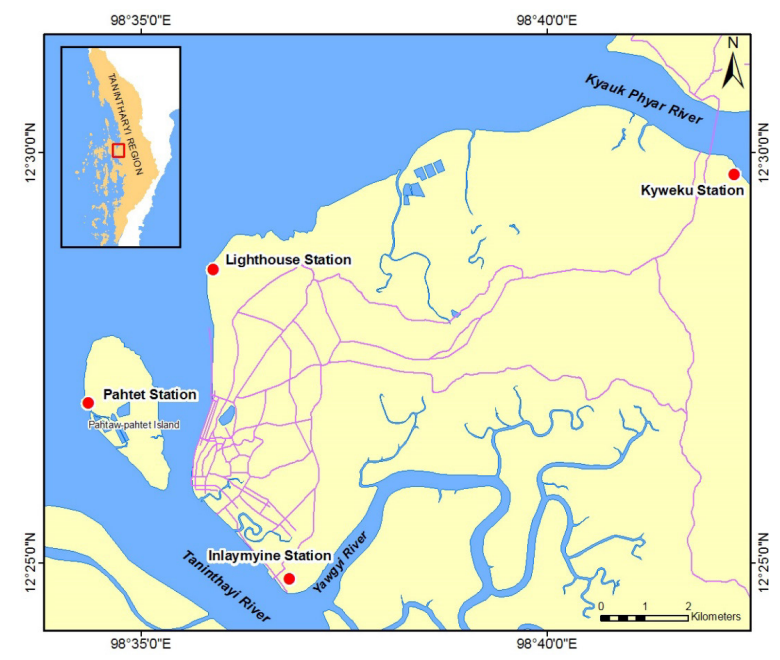

Figure I Map showing the location of study areas. 


\section{Sample collection and Preservation}

Mollusks (gastropods and bivalves) species were collected from five stations in mangrove swamp of Myeik coastal and adjacent areas, from July 2013 to March 2014.Triplicated samples were bimonthly collected. Measurement of shell height $(\mathrm{H})$, length (L), inflation (In), breadth (B), aperture length(LA) and aperture width (WA) were taken with digital vernier caliper (Precision $=0.01 \mathrm{~mm}$ ) ${ }^{1,2}$ After collection, the specimens were washed, cleaned and they were then preserved in $10 \%$ of naturalized formalin. After a few days, they are generally kept in 70\% alcohol for several days. After preserved, all the shells were washed again; cleaned and dried to storage the samples. And they were lightly rubbed with a small amount of olive oil applied with a tuft of cotton for taking photograph. And then, all specimens were deposited at Marine Science Museum of Myeik University.

\section{Identification}

The identification of gastropods and bivalves species was done mainly through the study of their conchological character such as the morphology of shells, their color, luster and teeth (cardinal and lateral). The literature used for the identification of gastropods and bivalves species were Morris, ${ }^{3}$ Melvin, ${ }^{4}$ Tantansiriwong, ${ }^{5}$ Soe Thu, ${ }^{6}$ Reid, ${ }^{1}$ Mar Lar Myo Sein, ${ }^{7}$ Aye Thida Thein, ${ }^{8}$ Tan and Sigurdsson, ${ }^{9}$ Poutiers, ${ }^{10}$ Taat Tun Thu, ${ }^{11}$ Carpenter, ${ }^{2} \mathrm{Ng}$ and Sivasothi, ${ }^{12}$ Oliver, ${ }^{13}$ Aye Thant Zin et al., ${ }^{14}$ and Naung Naung Oo. ${ }^{15}$

\section{Results}

A total of 29 species of mollusks were collected from the mangrove swamps of study areas during the study period (from July 2013 to March 2014)(Figure 2) (Figure 3). The composition of the species were 23 species belonging to 3 orders, 8 families, 14 genera under the class gastropoda and 6 species belonging to 3 orders, 5 families, 6 genera under the class bivalvia. In gastropod, 3 species of Neritidae, 4 species of Littorinidae, 1 species of Assimineidae, 4 species of Potamididae, 1 species of Naticidae, 1 species of Muricidae, 2 species of Nassariidae, 1 species of Melongenidae and 6 species of Ellobidae. In bivalves, 1 species of Arcidae, 1 species of Mytilidae, 2 species of Ostreidae, 1 species of Corbiculidae and one species of Veneridae were observed (Table 1) (Table 2).



Figure 2 Gastropods:(a) Dorsal view, (b) Ventral view; Figure I, Nerita lineata; Figure 2, Nerita funiculata; Figure 3, Dosita violaceae; Figure 4, Littoraria conica; Figure 5, Littoraria scarba; Figure 6, Littoraria melanostoma; Figure 7, Littoria strigata; Figure 8, Assiminea brevicula; Figure 9, Telescopium telescopium; Figure 10, Cerithidea cingulata; Figure II, Cerithidea obtusa; Figure 13, Cerithidea rhizophorarum; Figure 13, Natica trgrina; Figure 14, Thais rufotincta; Figure I5, Nassarius dorsatus; Figure 16, Nassarius jacksonianus; Figure, Pugilina ternatana; Figure 18, Ellobium aurisijudaei; Figure 19,Cassidula aurisifelis; Figure 20, Cassidula mustelina; Figure 2I, Pythia pantherina; Figure 22, Pythia scarabaeus; Figure 23, Melampus zonztus. 


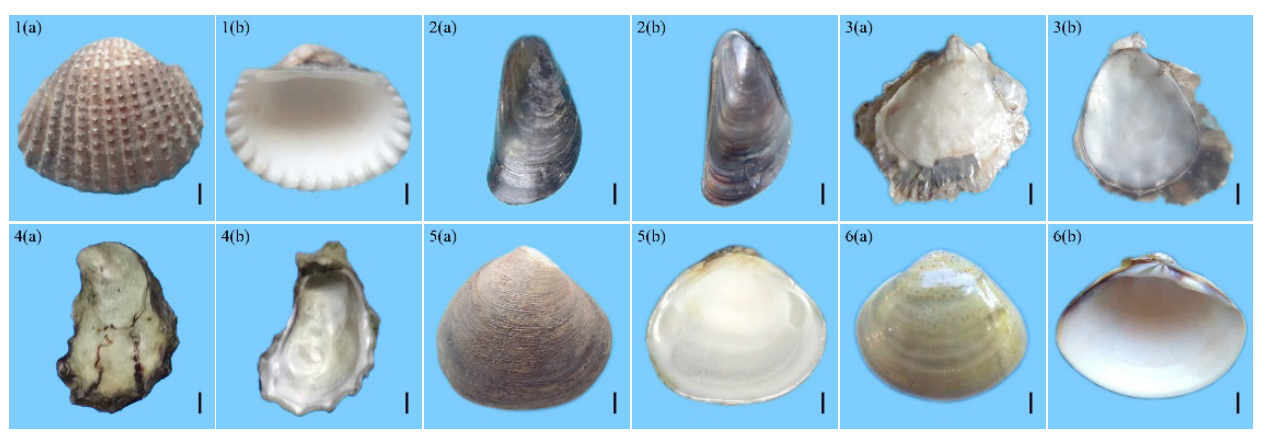

Figure 3 Bivalvess: (a) Dorsal view, (b) Ventral view; Figure I, Anadara granosa; Figure 2, Perna viridis; Figure 3, Planostrea pestigris; Figure 4, Saccostrea cuccullata; Figure 5, Polymesoda expansa; Figure 6, Meretrix meretrix.

Table I Classification list of gastropods occurring in the study areas.

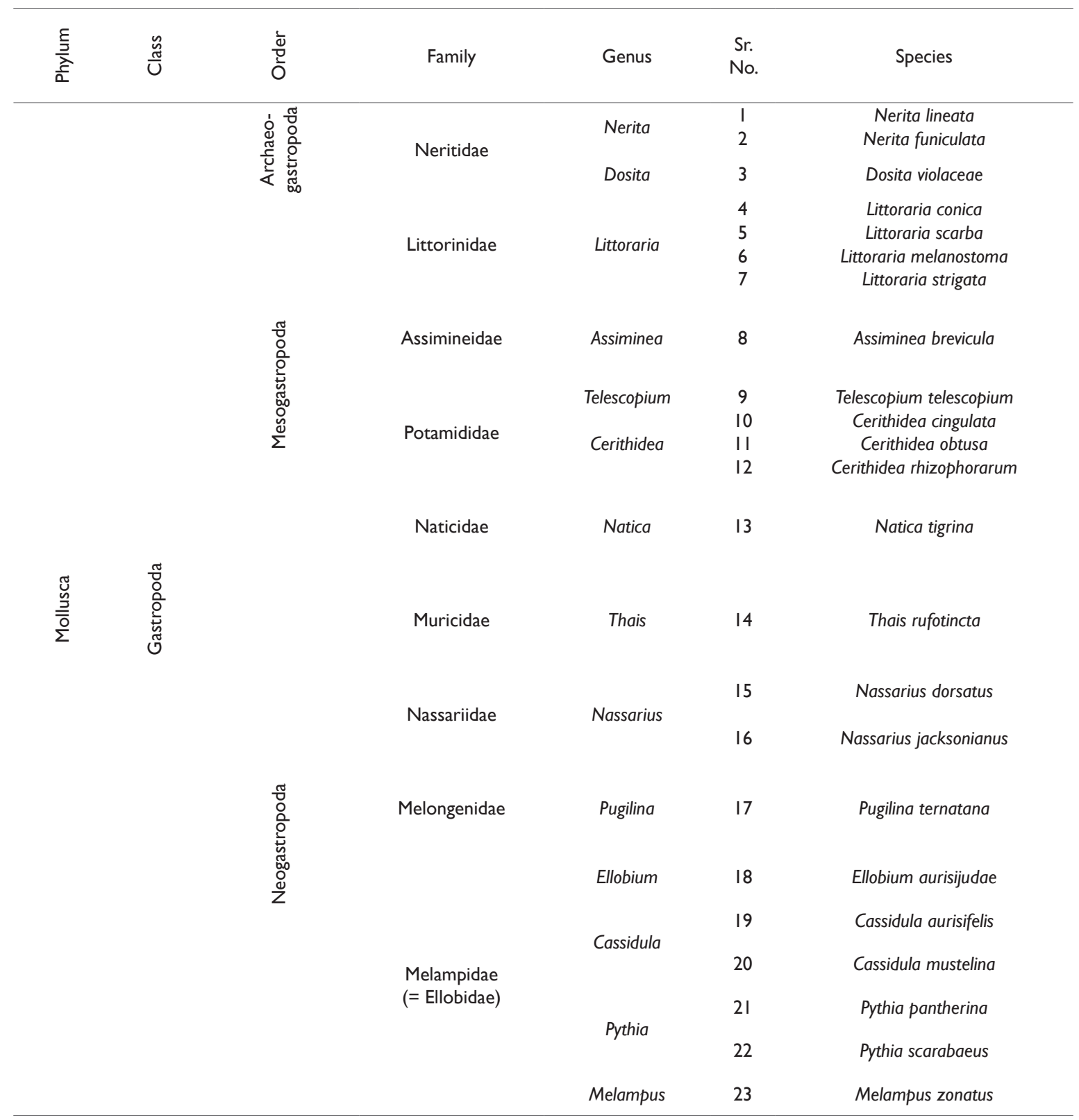


Table 2 Classification list of bivalves occurring in the study areas

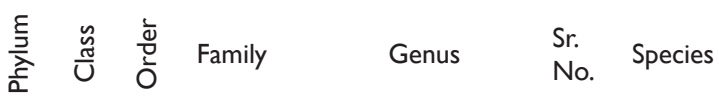

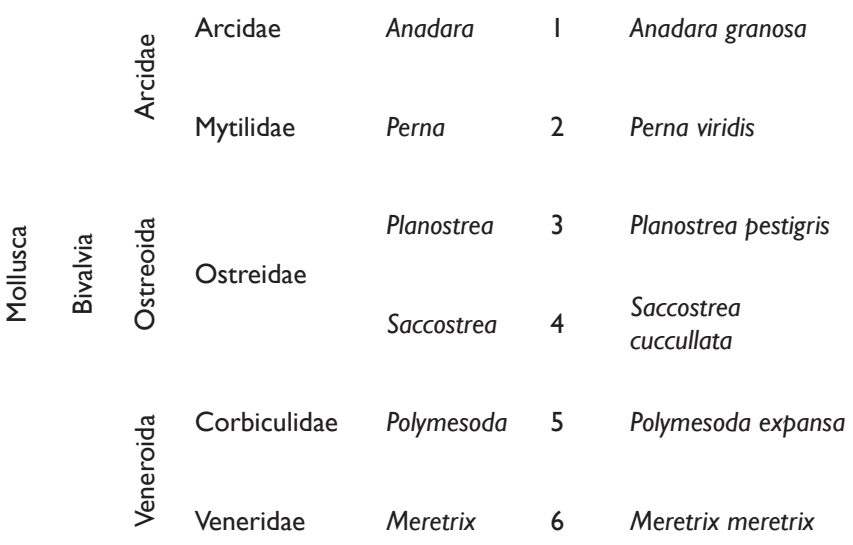

Morphological description of gastropods occurring in the study area

Nerita lineata Gmelin, 1791

Soe Thu 1980: 132, Pl.3, Figure 2; Aye Thida Thein 1982: 26, Figure 3; NaungNaungOo 2012:59, Figure 27.

Synonyms: Unknown.

Common name: Nerites.

FAO name: Lined nerite shell.

Local name: Kha-yuu-ma.

Measurement: H-5.12mm, B-18.86mm, LA-8.32mm, WA-11.8mm.

Description: Shell globe, solid and ovate, medium size and thick. Apex low. Shell sculptured with numerous striped spiral cords. Columella edge with 3-4 teeth. Parietal wall smooth, with slightly raised cords at edge adjoining body whorl. Outer lip sharp, slightly serrated and denticulated. Operculum is paucisipral with marginal nucleus. Colour of shell is grayish to yellow spot with spiral cords. Parietal wall is white with yellowish tinge. Outer lip black edge. Operculum is grayish.

Habitat: Intertidal zone.

Local distribution: Lighthouse, Pahtet (present study), Sinpone, Kayinthaung, Hnitkayin, Kawdut, Sitaw, ${ }^{15}$ Coco Island. ${ }^{8}$

World distribution: Guamas and Peru.

Economic importance: Edible and used as decoration materials.

Nerita funiculata Menke, 1850

Morrise 1952: 156, pl. 53, Figure 22; Aye Thida Thein 1982: 30, Figure 4; NaungNaungOo 2012: 62, Figure 30.

Synonyms: Unknown.

Common name: Nerites.
FAO name: Polished nerite.

Local name: Kha-yuu-ma.

Measurement: H-17.21mm, B-15.63mm, LA-6.62mm, WA-8.91mm.

Description: Shell globe and ovate, medium size and thick. Apex low. Shell sculpture with numerous striped fine spiral cords. Parietal wall have 4-6 small pustules and ridges on side adjoining body whorl. Inner lip of aperture with 4-5 teeth and outer lip blunt, and denticulated, usually with one prominent large tooth at upper corner. Operculum is paucisipral with marginal nucleus. Shell color is grayish with wavy bands of black and white. Outer lip of aperture with black and white edge. Operculum grayish with small granules.

Habitat: Intertidal zone

Local distribution: Lighthouse, Pahtet (present study), Sinpone, Kayinthaung, Hnitkayin, Kawdut, Sitaw, ${ }^{15}$ Coco Island ${ }^{8}$

World distribution: Guamas and Peru.

Economic importance: Edible and used as decoration materials.

Dosita violaceae Gmelin, 1791

Soe Thu 1980: 140, Pl.3, Figure 17; Aye Thida Thein 1982: 106, Figure 20.

Synonyms: Neritina violaceae Gmeli, 1971.

Common name: Brakish water nerit.

FAO name: Nerite.

Local name: Kha-yu-ma.

Measurement: H-19.16mm, B-13.23mm, LA-6.66 mm, WA$10.1 \mathrm{~mm}$.

Description: Shell solid and ovate, medium size and thin. No spire and surface smooth. The aperture is wide, with a broad but ventral view like a horse shoes shaped. The inner margin has 8-9 of weakly teeth, almost straight and outer lip sharp. Color varies patterns, scattering patterns of white, purple, brown, yellow and orange over the surface. Pariental wall brownish orange.

Habitat: Mangrove mud flat.

Local distribution: Kyweku, Lighthouse, Inlaymyine, Pahtet (present study), Pine Tree Island. ${ }^{6,8}$

World distribution: Japan.

Economic importance: Decorative material.

Littoraria conica Philippi, 1846

Reid 1984: 332, Figure. 9.60.

Synonyms: Unknown.

Common name: Priwinkle.

FAO name: None.

Local name: Kha-yu.

Measurement: H-20.16mm, B-14.98mm, LA-9.82mm, WA-7.59mm.

Description: Shell moderately thick, solid. Spire outline convex, first 3 whorl rounded, subsequent whorl become flattened. Sutures 
scarcely impressed. Columella moderate width and excavated. Shell colour variable, cream with dense pattern of brown flecks, aligned into axial stripes only on spire whorl.

Habitat: Attached to mangrove roots and leaves.

Local distribution: Kyweku, Lighthouse, Inlaymyine, Pahtet (present study), Southern Burma. ${ }^{1}$

World distribution: West coast of Malay Peninsula, north-eastern Sumatra, Java, Borneo and southern Vietnam.

Economic importance: Decorative materials.

Littoraria scarba Linnaeus, 1758

Morris 1952: 222, pl.67, Figure 8; Tantanasiriwong 1978: Figure 60; Soe Thu 1980: 143, Pl.3, Figure 18; Reid 1984:160, Figure 9.9; Poutiers 1998: 433, Figure 3.

Synonyms: Littorina scarba Linnaeus, 1758; Littorinopsis scarba Linnaeus, 1758; Littorina angulifera Lamarck, 1822.

Common name: Periwinkle.

FAO name: Rough periwinkle.

Local name: Kha-yu.

Measurement: H-21.88mm, B-16.2mm, LA-10.85mm, WA-8.46mm.

Description: Shell thin but solid, with a tall conical spire and low sculpture. Spire whorls convex, with slightly suture channeled and sharply pointed. Outer surface without nodules sculpture. Outer lip of aperture is thin and smooth. Columella smooth and operculum ovate with a few spiral coil and lateral nucleus. Outside of shell pale brown in color with irregular pattern of dark brown and black stripes. Aperture pale yellow with the outer dark pattern showing through.

Habitat: Intertidal zone (Mangrove root and leave).

Local distribution: Kyauku, Lighthouse, Inlaymyine, Pahtet (present study), Kyung Phyu, Ngapali, King Island, Iron and Elephinstone Island (Soe Thu, 1982).

World distribution: Indo-west pacific from East Africa, Madagascar and the Red sea, Polynesia, Japan, Hawaii, Queesland, New Caledinia, Zanzibar, Mauritius, Srilankan, Mollaccas, Singapore and Malaysia.

Economic importance: Decorative materials.

Littoraria melanostoma Gray, 1839

Tantanasiriwong 1978: Figure

56; Soe Thu 1980: 144, P1.3, Figure 19; Reid 1984: 314, Figure 9.55; Naung Naung Oo 2012: 86, Figure 51.

Synonyms: Unknown.

Common name: Black mouth littorine.

FAO name: Undulate periwinkle.

Local name: Kya-yu-bazat-mae.

Measurement: H-23.5mm, B-15.8mm, LA-10.85mm, WA-8.46mm.

Description: Shell thin, tall, conical with sharply pointed spire. Spire whorls are convex, with a narrow channeled, shallow suture. Columella smooth, straights interiorly and meeting the basal end of shell at acute angle.Aperture is pale yellow to whitish, with the outer dark pattern. Brown axial growth line. Columella white, sometimes stained brown or purple.

Habitat: Intertidal mangrove swamp (mangrove root and leave).

Local distribution: Kyweku, Lighthouse, Inlaymyine, Pahtet (present study), Ahlyat, Zeegone, Tawpon, Kyaikkhami, Siphone, ${ }^{15}$ Mergui Archipelago and King Island Bay. ${ }^{6}$

World distribution : Srilankan, Malaysia, Singapore, Borneo and Japan.

Economic importance: Decorative materials.

Littoraria strigata Philippi, 1846

Reid 1984: 383, Figure 9.77.

Synonyms: Unknown.

Common name: Priwinkle.

FAO name: None.

Local name: Kha-yu.

Measurement: H-11.32mm, B-9.43mm, LA-5.92mm, WA-5.29mm.

Description: Shell small, solid and moderately thick. Spire outline slightly convex and whorls rounded. Sutures impressed, peripheral keel absent. Aperture moderate width and excavated. Colour variable, creamy yellow to white with black or brown pattern, axial stripes.

Habitat: Intertidal mangrove swamp (mangrove root and leave).

Local distribution: Kyweku, Lighthouse, Inlaymyine, Pahtet (present study).

World distribution: South-Western Thailand, Tava, Sarawaks, Philippines.

Economic importance: Decorative materials.

Assiminea brevicula Pfeiffer, 1854

Tantanasiriwong 1978: Figure 61.

Synonyms: Unknown.

Common name: Red berry snail.

FAO name: None.

Local name: Kha-yu.

Measurement: H-4.95mm, B-3.75mm, LA-1.85mm, WA-1.42mm.

Description: Shell is small, spiral low. Aperture is ear shape, relatively small, with a short siphonal. Operculum rounded, with many spiral coils. It is bright red shell.

Habitat: On muddy and sandy substrate.

Local distribution: Kyweku, Lighthouse, Inlaymyine, Pahtet (present study).

World distribution: Singapore.

Economic importance: Decorative materials.

Telescopium telescopium Linnaeus, 1758 
Tantanasiriwong 1978: Figure 69; Soe Thu 1980:165, Pl.4, Figure 5; Poutiers 1998: 451, Figure 1; Oliver 2004: 52; Aye Thant Zin et.al 2007: 28, Figure 7; Naung Naung Oo 2012:103, Figure 63.

Synonyms: Potamides telescopium Linnaeus, 1758; Telescopium mauritsi Butot, 1954.

Common name: Horn shell.

FAO name: Telescope snail.

Local name: Kha-yu-zay-de or Kha-yu-kan-zaw.

Measurement: H-7.3mm, B-2.9mm, LA-2.13mm, WA-1.52mm

Description: Shell large high, thick, conical spire, board rather flat base. Several spiral grooves running along the whorl. Pale line represents at suture. Aperture is obliquely quadrangular, relatively small. Lower end of aperture sharply curves to siphonal canal. Outer lip not flared, thin and nearly smooth. Outside of shell dark brown to almost black. Columella is light brown or whitish.

Habitat: Intertidal (on mud substrates in mangrove forest).

Local distribution: $\quad$ Kyweku, Lighthouse, Inlaymyine, Pahtet (present study), Kawdut, Zeephuthaung, ${ }^{15}$ Kyauk Phyu, Kyaukalat, Mangmagan. ${ }^{6}$

World distribution: Indo- west pacific, from Madagascar, India and Sri Lankan, to Papua New Guinea: north to the Philippines and south to central Queensland.

Economic importance: Edible for food and use as decoration.

Cerithidea cingulata Gmelin, 1791 Tantanasiriwong 1978: Figure 73; Soe Thu 1980:165, P1.4, Figure 3; Poutiers 1998: 454, Figure 4; Oliver 2004: 52; Naung Naung Oo 2012:104, Figure 64.

Synonyms: Potamides cingulatus Gmelin, 1791; Tympanotonas fluviatilis Potiez and Michaud, 1838.

Common name: Horn shell.

FAO name: Girdled horn snail.

Local name: Kha-yu.

Measurement: H-23.5mm, B-8.84mm, LA-6.85mm, WA-3.99mm.

Description: Shell small, elongate to fusiform, deep suture and eroded apex. Body whorls are encircled by spiral ribs with granules, vertical ribs are prominent. Knob-like varix bears on the opposite side of aperture. The outer lip is thickened, expanded and arch. Two or three brown or white line per whole.

Habitat: Intertidal (on mud substrates in mangrove forest).

Local distribution: Kyweku, Lighthouse, Inlaymyine, Pahtet (present study), Zeegone, Tawpon, Kayinthaung, Setse, Kawdut, ${ }^{15}$ Coco Island. ${ }^{6}$

World distribution: Indo-west pacific, from Madagascar, India and Sri Lankan, to Papua New Guinea: north to the Philippines and south to central Queensland.

Economic importance: Use as decoration.

Cerithidae obtusa Lamarck, 1822

Tantanasiriwong 1978: fig.70; Poutiers 1998: 450, fig.6; Oliver 2004: 52; Naung Naung Oo 2012:105, Figure 64.
Synonyms: Potamides obtusus Lamarck, 1822

Common name: Horn shell.

FAO name: Girdled horn snail.

Local name: Kha-yu-oh-soke.

Measurement: H-41.2mm, B-25.73mm, LA-12.2mm, WA-10.13mm.

Description: Medium sized shell, thick and robust with moderately rounded bear: body whorl wide and rounded at periphery; outer lips is remarkable thick and flattened. Subcircular in outline, anterior siphonal canal short, open and oblique. Columella is narrow. Operculum is multi-spiral with central nucleus.

Coloration: Outside of shell is brown or dull purplish brown. Aperture is brownish; outer lip creamy.

Habitat: Intertidal (climbing up to tree and on mud substrates in mangrove forest).

Local distribution: Kyawku, Lighthouse, Inlaymyine, Pahtet (present study), Zeegone, Tawpon, Kayinthaung, Setse, Kawdut, ${ }^{15}$ Coco Island. ${ }^{6}$

World distribution: Indo-west Pacific, from Madagascar, India and Sri Lankan, to Papua New Guinea: north to the Philippines and south to central Queensland.

Economic importance: It is a delicious seafood as well as famous seafood in Myeik and used for decoration.

\section{Cerithidae rhizophorarum A.Adams, 1855} 5

Tantanasiriwong 1978: 14, Figure 71; Poutiers 1998: 454, Figure

Synonyms: Potamides quadrates Sowerby, 1866; Cerithidae obtusa Larmarck, 1822; Cerithidea quadrata Sowerby, 1866.

Common name: Horn shell.

FAO name: Quadrate horn snail.

Local name: Kha-yu-oh-soke.

Measurement: H-39.61mm, B-20.84mm, LA-8.82mm, WA$8.75 \mathrm{~mm}$.

Description: Medium sized shell, thin and trigal moderately quadrate base; outer lip of aperture is thin and flat. Subcircular in outline, anterior siphon canal short, open and quadrate. Columella is narrow. Operculum is multispiral with central nucleus. Outside of shell is yellowish or dull purplish brown. Aperture is dull purplish brown creamy lip with outer colour pattern showing through.

Habitat: In mangrove areas and brackish fishponds. Often climbing up to the trees.

Local distribution: Kyweku, Lighthouse, Inlaymyine, Pahtet (present study).

World distribution: Eastern part of the Indian ocean and the tropical west pacific, from the Andaman Sea to eastern Indonesia, north to Viet Nam and the Philippines, and South to Southern Indonesia.

Economic importance: Edible for food and use as decoration.

Natica tigrina Röding, 1758

Tantanasiriwong 1978: 11, Figure 142; Soe Thu 1980: 253, pl.7, 
Figure 14; Poutiers 1998: 514, Figure 1; Naung Naung Oo: 132, Figure 82.

Synonyms: Natica javana Lamarck, 1822; N.maculata Perry, 1811; N. maculosa Lamarck, 1822; N. pellistigrina Dunker, 1882; Tanea trgrina Röding, 1758; Tectonica tigrina Röding, 1758.

Common name: Moon snail.

FAO name: Tiger moon snail.

Local name: Kha-yu.

Measurement: H-18.3mm, B-15.37mm, LA-10.13mm, WA$6.55 \mathrm{~mm}$.

Description: Shell moderately thin, roughly pear-shaped in outline. Spire is a relatively tall, convex whorls and deeply impressed suture. Outer surface is smooth. Umbilicus is deep and narrow. Callus of the inner lip poorly developed. Operculum is calcareous with laterally nucleus. Outside of shell creamy white, covered with reddish brown blotches and spot. Umbilicus area and margins of the aperture white. Operculum is white.

Habitat: On sandy bottom.

Local distribution: Lighthouse (Present study), Thingangone, Tawpon, Zeegone, Asin, Sit, ${ }^{15}$ Kyaukalat and Maungmagan. ${ }^{6}$

World distribution: Indo- West Pacific, from the Mascareign Islands and India to Queensland.

Economic importance: Used as decorative materials.

Thais rufotincta Tan \& Sigurdsson, 1966

Tan \& Sigurdsson 1996:85, pl.2, Figure 2.

Synonyms: Unknown.

Common name: Rock shell or Oyster drill.

FAO name: None.

Local name: Sue-kha-yu.

Measurement: H-23.21mm, B-16.08mm, LA-12.8mm, WA-8.02mm.

Description: Shell is thick and solid. Apex is pointed. Spire is low and suture is deep. Shoulder is wide and rough. Columella is present and smooth. Aperture is wide and long. The upper lip is thin. Siphonal canal is present. Shell is whitish-yellow. Columella is creamy at the parietal region.

Habitat: Attached to mangrove tree and on the barnacle.

Local distribution: Kywe-Ku, Lighthouse (Present study), Kyeikkhami, Sinpone, Kayinthaung, Yathaetaung, Setse. ${ }^{16}$

World distribution: Indo-Pacific, Japan.

Economic importance: Used as decorative materials.

Nassarius dorsatus Röding, 1978

Tantanasiriwong 1978: Fig. 201; Poutiers 1998: 580, Figure 4.

Synonyms: Nassa canaliculata Lamarck, 1822; Tarazeuxi sunicolorus Kiener, 1841; Zexuxis dorsata Röding, 1798.

Common name: Nassa mud shell.

FAO name: Channeled nassa.

Local name: Kha-yu.
Measurement: H-38.1mm, B-18.12mm, LA-15.9mm, WA-8.76mm.

Description: Shell thick with smooth surface. Spire almost straight sided and a sharp, vertically ridged apex. Sculpture of anterior end has spiral grooves. Columella has weak folds. Inside of outer lip ridged. Operculum is paucispiral with apical nucleus. Colour of the shell varies from grayish to brown. Interior of aperture grey to brown. Edge of the outer lip is white.

Habitat: Muddy sand flat.

Local distribution: Kyweku, Lighthouse, Pahtet (present study).

World distribution: Eastern part of the Indian Ocean and the Tropical West Pacific, from the Andaman Sea to Melanesia; north to Japan and south to northern New South Wales.

Economic importance: Used as decorative materials.

Nassarius jacksonianus Quoy \& Gaimard, 1832

Tantanasiriwong 1978: Figure 20; Soe Thu 1980: 337, P1.9, Figure 24; Naung Naung Oo 2012: 201, Figure 141.

Synonyms: Unknown.

Common name: Dog whelk.

FAO name: White band nassa.

Local name: Kha-yu.

Measurement: H-20.64mm, B-13.69mm, LA-8.98mm, WA-5.13mm.

Description: Shell is small, solid, ovate and fusiform. The spire whorls are nodules, strong spiral grooves. Axial ribs are regularly on each whorl. Aperture is rounded, with very short and denticulate inside re-curved siphon canal. No umbilicus. Shell surface is brown with a distinct white band.

Habitat: On muddy sand flats.

Local distribution: Kyweku, Lighthouse (present study), Hnit Kayin, Kawdut, Asin, Zeephyuthaung, Sitaw, ${ }^{15}$ Kyauk Phyu. ${ }^{6}$

World distribution: Malaysia.

Economic importance: Used as decorative materials.

Pugilina ternatana Gmelin, 1791

Soe Thu 1980: 333, P1.9, Figure 20; Poutiers 1998: 586, Figure 4; NaungNaungOo, 2012: 205, Figure 144.

Synonyms: Hemifusus ternatanus Gmelin, 1791; Pugilina tuba Gmelin, 1791.

Common name: Melongenas.

FAO name: Ternate melongena.

Local name: Zay-de-kha-yu or Kha-yu-wet-taung.

Measurement: H-80.56mm, B-42.2 mm, LA-53.04mm, WA$20.2 \mathrm{~mm}$.

Description: Shell is large, solid, very tall heavy and fusiform. Spire is conical and high, with angulated shoulders and deeply incised sutures. Spire whorls sculpture with many fine and rough spiral cords and prominent and pointed nodules are present on each whorl. Aperture is long and narrow. Anterior siphon canal is very long. Shell colour is reddish brown. Columella is creamy.

Habitat: On muddy-sand. 
Local distribution: Lighthouse (present study), Kayinthaung, Sinpone, Kawdut, Zeephyuthaung, Sitaw. ${ }^{15}$

World distribution: Southeast Asia region, the tropical West Pacific and Eastern Indian Ocean.

Economic importance: Edible and used as decoration materials.

Ellobium aurisijudae Linnaeus, 1758

Tantanasiriwong 1978: 20, Figure 250; Soe Thu 1980: 472, Pl-13, Figure 40; Poutiers 1998: 643, Figure 3; Naung Naung Oo 2012: 521, Figure 174.

Synonyms: Auricula aurisjudae Linnaeus, 1758; Auricula judae Lamarck, 1822; Ellobium labrosum Röding, 1798; Elliobium subtile Röding, 1978.

Common name: Marsh snail.

FAO name: Judas ear cassidula.

Local name: Kha-yu-thit-swe.

Measurement: H-47.46mm, B-21.55mm, LA-24.4mm, WA-9.51mm.

Description: Sell is medium sized, solid, elongate-ovate in outline, not shouldered. Spire apex is blunt. Sculpture composed of numerous axial grooves and fine spiral lines. Outer lip of aperture is thick, flat and smooth. With a low swelling at about the middle and white is tree folds; posterior fold toothed, center fold oblique, large and angular, anterior fold weak and almost axial in direction. Outside of shell in light brown and whitish in the aperture.

Habitat: On mud substrate and dead tree trunks in mangrove.

Local distribution: Kyweku, Lighthouse, Inlaymyine, Pahtet (present study), Kyaukphyu, ${ }^{6}$ Hnitkyin. ${ }^{15}$

World distribution: Indian Ocean, Indo-Pacific, Malay Archipelago, Philippines, south to North Australia and Queensland.

Economic importance: Edible and used as decoration materials.

Cassidula aurisfelis Bruguiere, 1789

Melvin 1966: 106, pl. 43, Figure 21; Tantanasiriwong 1978: 20, Figure 257; NaungNaungOo 2012: 252, Figure 175.

Synonyms: Unknown.

Common name: Pulmonate snail.

FAO name: Flat lip cassidula.

Local name: Kha-yu-thit-swe.

Measurement: H-25.9mm, B-16.48mm, LA-15.12mm, WA-6.82mm.

Description: Shell is moderately solid, ovate, with a rather short conical spire and low sculpture. Outer surface is smooth. Aperture is somewhat like an ear in shape. Outer lip is thick and flat. Inner lip is tree folds; medium fold is strong. Outer lip has a raised margin. Operculum is absent. Shell surface is light brownish colour. Outer lip of aperture is creamy.

Habitat: On mud substrate and dead tree trunks in mangrove.

Local distribution: Kyweku, Inlaymyine (presentstudy), Sitaw $^{15}$
World distribution: China to Singapore.

Economic importance: Used as decorative materials.

Cassidula mustelina (Deshayes, 1830)

Tantanasiriwong 1978: 20, Figure 259.

Synonyms: Auricula rhodostoma Hombron\& Jacquinot, 1854; Cassidula nucleus Pollonera, 1898.

Common name: Pulmonate snail.

FAO name: Flat lip cassidula.

Local name: Kha-yu-thit-swe.

Measurement: H-19.19mm, B-12.27mm, LA-10.9mm, WA-4.17mm.

Description: Shell is moderately solid, ovate, with a rather short conical spire and low sculpture. Outer surface is smooth. Aperture is somewhat like an ear in shape. Outer lip is thick and flat. Inner lip is two folds. Operculum is absent. Shell surface is bright brownish colour. Outer lip of aperture is creamy.

Habitat: On mud substrate and dead tree trunks.

Local distribution: Kyweku, Inlaymyine (present study).

World distribution: Thailand.

Economic importance: Used as decorative materials.

Pythia pantherina Gray, 1847

Soe Thu 1980: 474, pl. 13, Figure 42; Naung Naung Oo 2012: 253, Figure 42.

Synonyms: Unknown.

Common name: Pythia snail.

FAO name: Plicatedellobid.

Local name: Kha-yu-thwar-kyae.

Measurement: H-27.58mm, B-24.19mm, LA-15.2mm, WA$5.9 \mathrm{~mm}$.

Description: Shell is globes, solid with a pointed spire whorl. Shell compressed dorsal ventrally with a flat lateral varix. The aperture is swollen and extended from the inflated body whorl. Outer lip is thin, flat and expanded outside. Inner lip is strongly denticulate with three folds. Aperture is small. Shell light creamy-green, with white bands along the outer lip.

Habitat: On mud substrate.

Local distribution: Kyweku (present study), Zeegon, Tawpon, Ahlat, Thingangone, Asin. ${ }^{15}$

World distribution: Philippines, western central pacific.

Economic importance: Used as decorative materials.

Pythia scarabaeus Linnaeus, 1758

Poutiers 1998: 645, Figure 1.

Synonyms: Pythia helicina Röding, 1798; Pythia pantherina A. Adams, 1851; Pythia reeceana Pfeiffer, 1853.

Common name: Pythia snail. 
FAO name: Pythia.

Local name: Kha-yu-thwar-kyae.

Measurement: H-25.76mm, B-21.42mm, LA-12.96mm, WA-5.9mm.

Description: Shell is globes, solid with a pointed spire whorl. Shell compressed dorsal ventrally with a flat lateral varix continuing from body whorl towards the apex. Outer lip is flat and less expanded outside, with 4 or 5 denticulate protruding inside the aperture. Aperture is narrow. Shell creamy-brown, with white bands along the outer lip.

Habitat: On muddy substrate.

Local distribution: Kyweku (present study).

World distribution: Tropical west Pacific, from western Indonesia to Polynesia, north to southern Japan and Taiwan and Australia.

Economic importance: Used as decorative materials.

Melampus zonatus Muhlfeldt, 1865

Tantanasiriwong 1978: 20, Figure 259.

Synonyms: Unknown.

Common name: Marsh snail.

FAO name: Flat lip cassidula.

Local name: Kha-yu

Measurement: H-10.65mm, B-6.47mm, LA-6.58mm, WA-2.78mm

Description: Shell is very small, thin and ovate. Outer surface is smooth. Outer lip of aperture sharp. Operculum is absent. Shell surface is bright brownish colour with white band. Outer lip of aperture is creamy.

Habitat: On mud substrate.

Local distribution: Kyweku, Inlaymyine (present study).

World distribution: Thailand.

Economic importance: Used as decorative materials.

Morphological description of bivalves occurring in the study areas

Anadara granosa Linnaeus, 1758

Mar Lar Myo Sein 1982: 71, P1.2, Figure 7; Tat Tun Thu 1998: 42, pl.4, Figure 1; Poutiers 1998: 147, Figure 16; Phoo Thet Su Win 2012: 107, pl.40, Figure 40; Sint Sint Hlaing 2012: 17, Figure 4.1.

Synonyms: Anadarabisenensis Schrenck and Reinhardt1958; Arca granosa Linnaeus 1758; Tegillarca granosa Linnaeus 1758.

Common name: Ark shell.

FAO name: Granular ark.

Local name: Gyin.

Measurement: $\mathrm{In}=26.49 \mathrm{~mm}, \mathrm{H}=26.65 \mathrm{~mm}, \mathrm{~L}=30.78 \mathrm{~mm}$.

Description: Shell equivalve, thick and solid, ovate, strongly inflated and medium in size. Umbones strongly protruding, cardinal area rather large. Periostracum rather thin and smooth. Internal margins with crenulations corresponding with the external radial ribs. No byssal gape. External and internal are white, covered with brown periostracum.
Habitat: On muddy bottoms, or in mangroves. Intertidal and shallow subtidal waters.

Local distribution: Lighthouse (present study), Arkan, Delta, Tensserim, Mergui Archipelago, ${ }^{7}$ Myeik, Dawei, ${ }^{11}$ Setse, Kayinthaung, ${ }^{16}$ Pyin Bu Gyi. ${ }^{17}$

World distribution: Malaysia, Indo-West Pacific.

Economic importance: It is a delicious seafood and used for decoration.

Perna viridis Linnaeus, 1758

Mar Lar Myo Sein 1982: 80, Pl.5, Figure 1; Tat Tun Thu 1998: 80, pl.3, Figure 1; Poutiers 1998: 172, Figure 3; Sint Sint Hlaing 2012: 27, Figure 4.6.

Synonyms: Mytilus smaragdinus Chemnitz, 1785; M. viridis Linnaeus, 1758.

Common name: Mussel.

FAO name: Asian brown mussel.

Local name: Kha- yu- nyo.

Measurement: In- $4.23 \mathrm{~mm}, \mathrm{H}-7.61 \mathrm{~mm}, \mathrm{~L}-12.53 \mathrm{~mm}$.

Description: Shell is thin, elongate and trigonal ovate. The beak is close to the anterior end and is a few teeth just inside the umbel. Outer surface nearly smooth apart from concentric growth marks and faint radial lines. It is covered with whitish under a bright Periostracum which is dark brownish green.

Habitat: Attached to barnacles and oyster at mangrove forest.

Local distribution: Kyweku, Lighthouse, Pahtet (present study), Delta, Tenasserim, Mergui Archipelago. ${ }^{7}$

World distribution: Northwestern Indian Ocean to the Tropical Western Pacific.

Economic importance: It is a delicious seafood and used for decoration.

\section{Planostrea pestigris Hanley, 1846}

Poutiers 1998: 231, Figure 3; Sint Sint Hlaing 2012: 33, Figure 4.9.

Synonyms: Crassostrea discoidea Awati and Rai, 1931; C.rivularis Gould, 1861; Ostrea palmipes Sowerby, 1871; O. paulucciae Crosse, 1869; O. pestigris Hanley, 1846.

Common name: Oyster.

FAO name: Palmate oyster.

Local name: Ka-mar-cut.

Measurement: In- 5.38mm, H- 26.75mm, L- 22.22mm.

Description: Shell rather thin, very compressed laterally. Commissure of valves smooth and flattish. Left (lower) valve shallowly convex, larger than right (upper) valve which is flattened or slightly convex. Surface of left valve with narrow, rounded radial riblets. Surface of right valve is relatively smooth. Outside of shell variably colored, creamy or grayish, interior white or cream with pearly luster.

Habitat: Attached to mangrove leaves and tree. 
Local distribution: Kyweku, Lighthouse, Inlaymyine, Pahtet (present study), Pyin Bu Gyi. ${ }^{17}$

World distribution: Indo- West Pacific.

Economic importance: Decorative materials.

\section{Saccostrea cuccullata Born, 1778}

Poutiers 1998: 232, Figure 4; PhooThetSu Win 2012: 124, pl. 48, Figure 48; Sint Sint Hlaing 2012: 35, Figure 4.10.

Synonyms: Cressostrea cuccullata Born, 1778; Ostrea cornucopiae Chemnitz, 1785; O. cornucopiaeformis Saville - kent, 1893; O.echinata Quoy and Gaimard, 1835; O. forskaelii Chemnitz, 1785; O. forskalli Gmelin, 1791; O. glomerata Gould, 1850; O. malabonensis Faustino, 1832; O. mordax Gould, 1850; O. spinosa Deshayes, 1836; Saxostrea amasa Iredale, 1939; S. commercialis Iredale and Roughley, 1933; S. gravid Iredale, 1939.

Common name: Oyster.

FAO name: Hooded oyster.

Local name: Kha- yin.

Measurement: In-11.52mm, H- 31.6mm, L-18.9mm.

Description: Shell stout, very variable in shape and size. Left (lower) valve generally deep with large attached area and strong radial ribs towards the periphery. Right (upper) valve flattish, fitting down into the plicate margin of the wider opposite valve. Exterior of shell dirty white to grayish brown, interior creamy white with deep purple margin.

Habitat: Attached to various hard substrates: rock and prop root of mangrove, etc.

Local distribution: Kyweku, Lighthouse, Pahtet (present study), Kayinthaung, Setse. ${ }^{16}$

World distribution: Widespread in the Indo- west Pacific, in the tropical eastern Atlantic.

Economic importance: Edible and used as decoration materials.

Polymesoda expansa Mousson, 1849 4.22

Poutiers 1989: 318, Figure 2, Sint Sint Hlaing 2012: 60, Figure

Synonyms: Cyrena ceylonica Chemnitz, 1782; Geloina expansa Mousson, 1849; Polymesoda proxima Prime, 1864.

Common name: Marsh clam.

FAO name: Broad geloina.

Local name: Wintnarr.

Measurement: In-21.06mm, H-32.48mm, L- 35.47mm.

Description: Shell equivalve, trigonal-ovate and distinctly expanded posterior. Umbones inflated, in front of the midline of shell. Outer surface of valves concentrically striated with a faint radial fold. Periostracum thick and fibrous. Hinge teeth moderately strong. Pallial sinus inconspicuous. Outside of shell is the greenish to yellowish brown Periostracum. Inner chalky or porcelaneous white.

Habitat: In muddy, brackish area of mangrove swamps.
Local distribution: Kyweku, Lighthouse, Inlaymyine (present study), Pyin Bu Gyi. ${ }^{17}$

World distribution: Indo-west pacific.

Economic importance: It is a delicious seafood and used for decoration.

\section{Meretrix meretrix Linnaeus, 1758}

Mar Lar Myo Sein 1982: 216, pl.23, Figure 3, Tat Tun Thu 1989: 156, pl. xxv, Figure 2, Poutiers 1989: 337, Figure 17, Sint Sint Hlaing 2012: 81, Figure 4.32.

Synonyms: Meretrix lamarckii Deshayes, 1853; M. lusoria Röding, 1758; M. petechialis Lamarck, 1818.

Common name: Clams.

FAO name: Asiatic hard clam.

Local name: Shut.

Measurement: In- $17.62 \mathrm{~mm}, \mathrm{H}-27.8 \mathrm{~mm}, \mathrm{~L}-31.91 \mathrm{~mm}$.

Description: The shell is trigonal ovate, thick and heavy. Umbones poorly inflated. Lunule poorly defined and escutcheon indistinct. Outer surface of shell smooth. eriostracum smooth and glossy. Hinge 3 cardinal teeth and well developed anterior lateral teeth. Pallial sinus broad and rather shallow. Internal margin smooth. Outside of shell very variable in colour.

Habitat: In sand and muddy- sand bottom.

Local distribution: Lighthouse (present study), Pyin Bu Gyi, Pyin, ${ }^{17}$ Dawei, Myeik, Kawthaung. ${ }^{11}$

World distribution: Widespread in the Indo- west Pacific, from East Africa to the Philippines: north to Japan and South to Indonesia.

Economic importance: It is a delicious seafood and used for decoration.

\section{Discussion}

Mollusks (gastropods and bivalves) species are important associated species of mangrove forest. They were collected bimonthly from four stations in mangrove swamp of Myeik coastal and adjacent areas, from July 2013 to March 2014. The mangrove associated species of gastropods and bivalves were identified and listed. In the present study, a total of 23 species belonging to 3 orders, 8 families, 14 genera under the class Gastropoda and 6 species belonging to 3 orders, 5 families, 6 genera under the class Bivalvia were observed from the mangrove swamps of study areas during the study period. According to this study, Gastropods are typically one of the most dominant groups in mangrove swamp than the bivalves Dewiyanti and Sofyatuddin ${ }^{18}$ explained that gastropods had high abundance and distribution probably due to their mobile characteristic.

Burmese Marine gastropods were studied by Soe Thu. ${ }^{6} \mathrm{He}$ presented a total of 142 genera and 456 exclusively marine species of belonging to families of 10 orders falling under 3 subclasses of the class gastropod from the intertidal zones of Arakean (Yakhein), Delta region and Tenasserin coast (Taninthayi Region). Naung Naung $\mathrm{Oo}^{15}$ was also recorded total of 130 species belonging to 3 orders, 39 families, 68 genera under the class Gastropoda from Mon coastal areas. 
Mar Lar Myo Seine ${ }^{7}$ observed Burmese marine bivalves that a total of 70 genera and 174 exclusively marine species belonging to 31 families and 18 super families of five orders falling under subclass Lamellibranchia of class Bivalvia, a total of 52 genera and 89 exclusively marine species belonging to 27 families and 18 super families of six orders falling under the class Bivalvia from Dawei, Myeik and Kawthaung along Taninthayi region, ${ }^{11} 36$ species of marine bivalves from Pyin Bu Gyi village, Palaw Township, Taninthayi region, ${ }^{17}$ a total of 14 taxa of the marine pelecypods from Mon coastal areas. ${ }^{19}$

The others studied of mollusks in the Myanmar, 73 species of mollusks in the intertidal zone of Myeik coastal $\operatorname{areas}^{20}$ a total of 33 species of gastropods and 17 species of pelecypods were recorded from Setse and Kyeikhame coastal areas by PhooThetSu Win. ${ }^{12}$ Aye Thant $\operatorname{Zin}^{14}$ working on preliminary survey of gastropods and pelecypods around Sin-ma village, Pathein Township who observed that 26 species of gastropods and 8 species of pelecypods. However, there is no comprehensive list of mollusks found in mangrove areas.

The numerous investigation of mangroves associated mollusks in the world wide, 39 species of gastropods in an Australian mangrove, 28 species in the Chinese mangrove, 23 mollusks species from the mangrove forest in Hong Kong, 29 species of bivalves from the mangrove root systems on the Atlantic coast of Colombia and woodboring bivalves are also common in the mangrove forest, 10 species of teredinids and 1 pholadid in several mangroves along the west coast and 44 species of Sematan mangrove forest of Malaysia ${ }^{21}$ and 15 species listed in west coast of India ${ }^{22}$ and a total of 55 species of mollusks representing 13 orders, 30 families and 39 genera from the mangroves of Uran. ${ }^{23}$ Mollusks was one of the most abundant groups of invertebrates in the mangrove community inhabit both forest and mudflat habits. ${ }^{24}$

In the present study, 29 species of mollusk were recorded in the mangrove swamp of Myeik adjacent areas, which include 23 species of gastropods and 6 species of bivalves. It is the natural mangrove areas, Avicennia spp - more common and Rhizophora spp - rare because local people are selected cutting it for charcoal and building of house and bridges etc. The observation of Suaresh ${ }^{21}$ recorded that 11 species of mollusks, which includes 8 species of gastropods and 3 species of bivalves, in the artificial mangrove of Pazhayar back water canal, southeast coast of India. In this area, they planted the two mangrove species of Avicennia spp and Rhizophora spp. for 0.5 hectare around the back water canal. Camargo Maia and Coutinho ${ }^{25}$ explained that the distribution of mollusks is highly correlated with tree density and composition of vegetal species. Likewise, Dewiyanti and Sofyatuddin ${ }^{18}$ point out the abundance of gastropods increased with increasing vegetation age, but the age of vegetation did not affect the abundance of bivalves. In addition, Hein Zar Htwe and War War $\mathrm{Soe}^{26}$ concluded that different species assemblages of gastropods and bivalves in various sites were correlated with environmental parameters.

Marine gastropods and bivalves are diverse in various environments. Among them, some mollusks fauna was live in mangrove swamp and plants. The species of Littoraria spp, Nerita lineata, Assiminea brevicula, Cerithidea spp were common in study areas that were noticeably occurred in the muddy substratum as well as on the stem and roots system of mangroves along the various tidal marks. Littoraria spp, Nerita spp, Cerithidea spp were attached to the mangrove vegetation up to 1.5 meter height. Telescopium telescopium was common on the muddy banks and soft silt mud flats. Likewise, Natica tigrina, Nassarius spp and Pugilina ternatana were found prowling on the mudflats at low tide. Thais were commonly found associated with barnacles because it is predators. The ellobiids primarily occurred deaden wood and mud in the mangrove; mostly found the high tide mark. Polymesoda expansa was observed shallowly buried in mud at above high tide mark while Meretrix meretrix was found in sandy at low tide. The diversity of oysters and mussels species in mangrove root system is comparable to or even denser than in others intertidal fertile substrate. Some of mollusks species in present observation were found on mud banks and flats, sand dune and flats, prop-roots and pneumatophores of mangroves and some species were found attached on hard substratum of mangrove's bark.

Gastropods and bivalves are used for various purposes like food, ornamental, poultry feed and source of lime. In the present study areas, Nerita linata, N. funiculata, Telescopium telescopium, Cerithidea obtuse, C. rhizophorarum, Pugilina ternatana, Anadara granosa, Perna viridis, Polymesoda expansa and Meretrix meretrix are collected for local consumption. The most economic important species are C. obtuse, C. rhizophorarum, P. ternatana, A. granosa, $P$. viridis, $P$. expansa and $M$. meretrix. Especially, Cerithidae spp. was exported to Thailand and $P$. ternatana and A. granosa were also exported to China. Most of the people are used this shell as home decorative materials, keychain, raw materials for cosmetics, necklace and ornamental items etc. And most of the shell sold as decorative materials at souvenirs shop along the coastal beaches of Myanmar.

\section{Conclusion}

This study provides baseline information on the morphology of gastropods and bivalves in the mangrove swamp of Myeik coastal area. In this study, 29 species of mollusks were identified, which include 23 species of gastropods and 6 species of bivalves. Gastropods are typically one of the dominant groups in mangrove swamp than the bivalves. And these species were provided not only local utilization but also ecological indicator of mangrove community in study areas.

\section{Acknowledgements}

I would like to express my sincere thanks to my teachers, colleagues and students for their positively advices, needful help and kindly support me in many ways during this study, Department of Marine Science, Myeik University. Many thanks go to Dr Naung Naung Oo, Assistant Lecturer of the Department of Marine Science, Mawlamyine University, for his assistance in preparations of the manuscript. And I am also indebted to local people for their sharing of traditional knowledge. I would like to heartful thanks my beloved parents, U Kyi Ho and Daw Ky in Nyunt, for their physical, moral and financial supports throughout this study.

\section{Conflicts of interest}

The author declares that there are no conflicts of interest.

\section{References}

1. Reid DG. The systematic and ecology of the mangrove-dwelling Littoraria species (Gastropoda: Littorinidae) in the Indo-Pacific. PhD thesis, James Cook University. 1984.

2. Carpenter KE. The Living Marine Resources of the Western Central Atlantic. FAO, Rome. 2002, p. 26-147. 
3. Morris PAA. Field Guide to Pacific Coast Shells. Houghton Mifflin Company, Boston; 1952. 296 p.

4. Melvin AG. Charles E. Sea Shells of the world. Tuttle Co. Inc. 1966. 167 p.

5. Tantannasiriwong R. An illustrated checklist of marine shelled gastropods from Phuket Island, adjacent mainland and offshore Islands, western Peninsular Thailand. Bull Mar Biol Cent Phuket, Thailand. 1978;21:1-22.

6. Soe Thu. Taxonomy and distribution of Burmese marine gastropods Unpublished M.Sc. Thesis. Department of Zoology, Arts and Science University, Rangoon.1980.

7. Mar Lar Myo Sein. Taxonomy and distribution of Burmese marine bivalves. Unpublished M.Sc. Thesis. Department of Zoology, Rangoon University, Rangoon.1982.

8. Aye Thida Thein. The taxonomic studies on the Burmese Marine Nerites (Gastropoda: Neitidae). Unpublished M.Sc. Thesis. Department of Zoology, University of Rangoon.1982.

9. Tan KS, Sigurdsson JB. Two New species of Thais (Mollusca: Neogastropoda: Muricidae) from peninsular Malaysia and Singapore, with Notes on T tissoti (Petit, 1852), T. blanfordi (Melvill, 1893) from Bombay, India. The raffles bulletin of zoology. 1996;44(1):77-107.

10. Poutiers JM. Gastropods and Bivalves of the Western Central Pacific, FAO, Rome. 1998. p. 123-686.

11. Taat Tun Thu. Taxonomic studied on some marine bivalves of Dawei, Myeik and Kawthaung along Taninthayi Coast. Unpublished M.Sc. Thesis. Department of Zoology, Yangon University, Yangon,1998.

12. Ng PKL, N Sivasothi. Guide to the Mangroves of Singapore II (Animals Diversity). Raffles Museum of Bioversity Research, Department of biological Sciences. The National University of Singapore. 2002. p. 101128.

13. Oliver APH. Guild to the Seashells of the world. Octopus publishing Group Ltd, 2-4 Heron Quays, London. 2004; 320 p.

14. Aye Thant Zin, Lai LaiKhaing, Cho Cho Lwin. Perliminary survey of gastropods and Pelecypods around the Sin-Ma village, Pathein Township. Unpublished Term Paper. Department of Zoology, Pathein University, Pathein, Myanmar, 2007. 33 p

15. Naung Naung Oo. Study on the Marine gastropods from Mom Coastal areas. Unpublished. M.Res. Thesis. Department of Marine Science, Mawlamyine University. 2012.
16. Phoo Thet Su Win. Study on the marine gastropods and pelecypods from Kyeikkhami and Setse coastal areas. Unpublished M.Sc. Thesis. Department of Marine Science. Mawlamyine University, Mawlamyine. 2012.

17. Sint Sint Hlaing. Study on the bivalves near the shell dunes near Pyin Bu Gyi village, Palaw Township Tanintharyi Region. Unpublished M.Sc. Thesis. Department of Marine Science, Myeik University, Myeik. 2012.

18. Dewiyanti IK Sofyatuddin. Diversity of Gastropods and Bivlves in mangroves ecosystem rehabilitation areas in Aceh Besar and Banda Acesh Dristricts, Indonesia. 2012.

19. Phoo ThetS u Win. Study on the marine pelecypods from Mom coastal areas. Unpublished M.Res. Thesis. Department of Marine Science. Mawlamyine University, Mawlamyine. 2013.

20. War War Soe. Ecology of soft-bottom macrobenthic faunal communities in the intertidal zone of Myeik coastal areas. Unpublished PhD Dissertation. Department of marine science, Mawlamyine university. 2013.

21. Suaresh MS, Arularasan K, Ponnusamy. Distribution of molluscan fauna in the artificial mangroves of Pazahayar back water canal, Southeast Coast of India. Advances in Applied Science Research.2012; 3(3):1795-1798.

22. Khade SN, UH Mane. Diversity of Bivalves and Gastropod, Molluscs of some localities from Raigad district, Maharahtra, west coast of India. Recent Research in Sicence and Technology. 2012;4(10):43-48.

23. Pawer PR. Molluscan Diversity in Mangrove Ecosystem of Uran (Raigad), Navi Mumbai, Maharashtra West coast of India. Bull Environ Pharmacol Life Sci. 2012;1(6):55-59.

24. Hogarth PJ. The biology of mangroves. Oxford University press, Oxford. 1999, 228 p.

25. Carmargomaia R, R Coutinho. The influence of mangrove structure on the spatial distribution of Melampuscoffeus (Gastropoda: Ellobidae) in Brazilian estuaries. Pan - American Journal of Aquatic Science. 2013;8(1):21-29.

26. Hein Zar Htwe, War War Soe. Community Structure of Marine Gastropods from Mangrove Swamp in Myeik areas. University Research Journal. 2014;7(6):287-300. 